\title{
Reflectivity, Reflexivity and Situated Reflective Practice
}

\section{Introduction}

This paper enters the debate and discussion on the nature of reflective practice. During a study of professional training within a major corporation it became clear that standard references to individual trainers' acts of reflection were only partially successful in describing the data, there was a gap in ways reflection explored interactions within the corporation's systems and organisation. For this we have turned to social theories of structuration and reflexivity. In particular, we move within Giddens's (1984) theory of structuration, which sees social life as an interplay of agency and structure. Our interest lies in the reflective practice of professionals within their 'field of professionalism', and the emergence of a form of personal reflection we call 'Situated Reflective Practice' (SRP). We propose Giddens' structuration theory as one 'lens' through which to view these reflective processes.

For Giddens, social structure and human agency are complementary forces, structures shape human action and human action can in turn transform social structures. Giddens's theory has structuralist leanings, and uses this interactive, circular, recursive, notion of human actions that are both constrained and enabled by structures. The ability of an agent to consciously grasp his or her place in the social structure is referred to as 'reflexivity', and recognises actors as having knowledge that is both reflexive and situated (Giddens \& Pierson, 1998). Reflexivity has come to mean an act of selfreference where self-examination entails the capacity of an individual to recognise forces of socialisation and the capacity to shift her or his place in the organisational structure. For Giddens, actors are not inherently predisposed to sustained reasoning or existential reflection on the meaning of their conduct from moment to moment in everyday life. Rather, 'discursive consciousness' emerges at critical times - expected or unexpected. In these circumstances,

Actors mobilise their efforts and focus their thoughts on responses to problems, which will diminish their anxiety, and ultimately bring about social change (Giddens \& Pierson, 1998, pp. 134-5).

\section{Reflexivity, reflectivity and SRP}

There is considerable debate about whether reflexivity and reflection refer to the same notion (Parton \& O’Byrne, 2000; Taylor \& White, 2000). For example, in Pease \& Fook (1999), reflection and reflexivity are used as interchangeable concepts, written as 
'critical reflection/ reflexivity' in the index. Closer to our distinctions, Rennie (2009) defines reflexivity in terms of self-awareness - and a gauge of personal agency within that self-awareness. In a similar vein, Fook (2002) takes on an approach to reflexivity as a stance, being able to locate oneself within a structural picture, appreciating how one's own self relates to the organisation. This latter denotation is broadly the line we follow here, where reflexivity relates to understandings of the complex relationships between individuals and social systems at micro and macro levels. That is, the capacity of the individual to position him or herself within the broader social and organisational causes of particular problems.

'Reflectivity', on the other hand, retains its reference to a process - the act reflecting on practice. This sense of reflection is a practice skill, a process used by practitioners to enable them to enhance and research their practice (Fook, 1996, 1999). Practitioners are encouraged to reflect on critical incidents in their practice and to develop an 'ability to build... a generalised theory about [his/her] own behaviour in similar situations’ (Fook, 1999, p. 197). In discussing reflective practice, Briggs (1999) uses an 'enhanced mirror' analogy, suggesting that 'reflection in professional practice gives back not what it is, but what it might be, an improvement on the original' (p6).

That said, neither of these terms has served to capture the sense emerging from the data we were generating with practitioners. In our research, we found that the usual expressions and examples of reflective practice were too individually self-referential, too 'context parochial', while the notion of reflexivity was too technical and abstract. This work, then, gave rise to the nature and dimensions of situated reflective practice, which seeks a stronger combination of both: a personalisation of structural agency. In discussing situated reflection we are not minimising the role of the practitioner, the 'inner reflector', but are bringing further into the picture the context of practice, Bourdieu's (1984) 'field'. Nor are we denying the 'structural stance' of the practitioner, simply grounding it in ruminative self-awareness and self-development. For Bourdieu, the field is the structured social space in which an individual undertakes practice, and we see SRP to be the practitioner's construction of self in relation to this context.

Of course, both Bourdieu and Giddens have their share of critics; from the political left and right, from social theorists and philosophers. Our interest lies in the struggles of our participants in this research, the nature of their reflective practice, as they wrestle with the structural constraints of their professional field. We see the role of the researcher as an enabling co-construction, taking account of the ways people consciously and 
unconsciously construct their own sense of social reality. We draw illustrative examples from interviews with fifteen educators charged with delivering teaching and training within a large corporation, and discuss these examples in terms of perceived 'structural distance' between the 'us' and 'them' within the corporate organisation. Seeing oneself in relation to the organisation can be illuminating in terms of personal capacities to effect change, personal needs and development, progress and ambition.

\section{What is meant by situated reflection?}

As noted above, much of the discussion of the nature of reflective practice has focussed on the intensely subjective 'internal worlds' of reflective practitioners. 'Reflection in action' and 'reflection on action' are those reflective episodes where there is 'thinking with a purpose' (Moon, 2005): The reference says 2004 the cogitation and deliberation on particular issues as a means of sorting complex and ill-structured thoughts, perceptions, ideas. The purpose behind the act of reflection is to reduce the complexity, and hence the unpredictability, of the issues involved, to find a route out of the complexity. In these pictures of reflection, little is actually made of the broad context, the situation, in which the person finds themselves.

We discuss the study in some detail below but, as an example of situated reflective practice in this sense, Moira observed during her interview,

Moira: This training role is relatively new as far as I am concerned. I have been asked [by the corporation] to take on board something that is now quite a big part of what I do at work - and what I want to do is make sure that I am any good at it, before I consider anything else in this place.

For Moira, her tendency is to take stock, test out where she is in her role before taking any further actions. This was a common thread through the interviews, where structural issues were raised and discussed, where the interviews seemed to act as a tool for selfmonitoring, generating some increased self-awareness within the interviewee's responses in terms of his or her role and place in the system.

Our notion of SRP builds on ideas from Schön (1987), Kolb (1984), Gibbs (1988), and seeks to add to the body of knowledge in a way that enables people to make sense of their world by observing the prevailing extended or external influences. It does not seek to replace the traditional ideas in relation to reflective practice, but to add to them, provide a situational context. Elsewhere, we (Authors, 2011) have delineated a situational context as being entailed by the: 
(1) Setting: the broad location, the physical environment, the surroundings, the time, systems, access and availability of information, the ambiance

(2) Social: the working/ learning community, its history, ethos, the roles, responsibilities, relationships, tasks, expectations, other people, what the participants are actually doing, their goals, the activities involved

(3) Personal/ Individual: individual dispositions, skills, competencies, participants' mental and physical states, intentions, moods, engagement, expertise.

Our sense of situational context is interactional: in professional settings, context is a relational property among people, place and activities. This view argues that the scope of contextual features is defined dynamically, context is relevant to particular settings, instances of action and particular parties to that action: context and activity are not separable. That is, context, situation, is embedded in activity and arises from it. Taking these elements one at a time:

(1) Setting: The physical surroundings are important. A hospital ward brings its own pressures for a nurse; a raked auditorium for a novice lecturer; a night-lit street for a new police constable; a motorway hard-shoulder for a young paramedic, a disreputable-looking squat for a youth worker. In our sense of 'situated reflection', it is a mistake, an over-simplification, to assume that reflection is agnostic to the physical settings in which professional life takes place.

(2) Social: A social context is also task-dependent. For students to listen and take notes in lecture mode is different to working at small-group mini-projects or making a presentation to a class of peers; a laboratory worker undertaking a lab-based experiment is different to conducting off-site fieldwork. In each of these, the 'relational formality' within employment hierarchies, and also between peers, is different and provides different task-contexts in which reflection takes place (or not).

(3) Personal/Individual: It is part of the overall discussions of reflective practice that people can be seen to have discernible styles of reflection. Moon (2005), for instance, discusses 'depth' as a dimension of reflection, others discuss breadth, complexity, levels of control, and so on. Our sense of situated reflection is that individuals respond in different ways to the situations in which they operate, so it is not just the 'reflective style' that matters, but also the person's perceptions and appreciation of the situation.

We use the schematic in figure 1 to represent this. 
Figure 1 about here please

\section{The nature of professional contexts, cultures, situations}

Situated Reflective Practice offers an additional perspective to that of the traditional forms of reflective practice because it is concerned with the way in which people, a social group or an organisation is behaving, and the impact of this upon a reflective individual, as opposed to the simple to considerations of his or her directed actions. The distinction between Reflection-re-Action, Reflection-re-Inaction and the more familiar Reflection-in-Action or Reflection-on-Action is that the focus of attention might be far removed from the person experiencing it. The essential quality of SRP is concerned with the changes in, or the emergence of a situation that affects that individual, through no immediate or direct design, action or fault of the perceiver. In other words, it focuses upon external events that creep into our lives, commonly uninvited, or are part of the institutional structures to which we subscribe when taking a professional role. Although often, but not exclusively, 'situations' relate to the ways in which a social group or an organisation is behaving, it can also relate to the more traditional examples of reflective practice that feature, for example, within classrooms or other learning and teaching arenas. The critical difference is the influence of a pressing external context that impacts upon an individual, as opposed to people reflecting upon something that they have done themselves, something for which they are, or have been, responsible. The distinction between Reflection-re-Action (or inaction) and Reflection-in-Action or Reflection-on-Action (Schön, 1987) is that the focus of attention may have little to do with the observer directly. They may have no control over the situation in which they are participating. In fact, the perceived situation may not be affecting them; at least not at that particular moment. An illustration is as follows: during his semi-structured research interview, David was asked, 'What kinds of difficulties have you experienced in acting on your reflections?' David is a professional educational trainer and identified an inability to make changes to a particular corporate training package. He explained that:

'In relation to reflective practice in terms of ELS [the training package], there is not a lot I will be able to change, to be honest with you. It's a corporate package and it has to be dealt with that way. But, I suppose, maybe the way I pitch that eventually could be different...' 
David's sense of an inability to make changes stems from the corporate body's needs to ensure that all its trainees are taught exactly the same topics in more or less the same way. He continued:

'We are corporate, so we all do exactly the same thing. So, it doesn't matter if I decide tomorrow to take annual leave because another instructor will know where I left off and will carry on exactly the same and will deliver exactly the same lesson in exactly the same way and use the same practices.'

Arguably, no amount of reflective practice at David's level will result in this types of course being changed, and would have little direct impact upon practice. The content is not negotiable: the organisation is keen to ensure the aims and objectives of the training course are recorded and 'version control' is strictly adhered to and recorded. If the trainer believes that a particular group would benefit from the introduction of further topics, this would not be permitted. That said, in the course of his reflections David muses that, while he may not be able to alter the content, he might be able to shape, nuance, its presentation.

\section{The study}

This study was part of a tranche of work into professional education and training (Authors, 2011). The participants were members of a group of trainers within a large organisation who had attended a central London college course and studied towards a qualification in Preparing to Teach in the Lifelong Learning Sector (PTLLS). There were 15 participants on the course and all 15 (nine male, six female) agreed to be interviewed about their experiences of training, their reflective practice and how it informed practice in their training roles. The anonymised participants are shown in figure 1 , as follows.

Figure 2 about her please, list of participants

None of us, as researchers and authors, had direct teaching involvement with the group, initial contact was made through email with the permissions of the organisation involved, and individual interviews were arranged. The participants were given a choice of location in which to be interviewed and, as a result, interviews took place in various classrooms or office locations within Greater London, some (as a last resort) actually in a quiet corner within the (large) corporate restaurant. Where possible, the location was 
chosen to best suit the wishes of the participants. Each interview was transcribed and our inductive analysis generated a series of key themes. As these themes grew in clarity we became increasingly interested in forms of reflection where the interviewees felt hamstrung, to a large degree rendered inactive by forces and circumstances at the limits of their control.

The research was conducted within the full ethical approval of the university concerned, and the corporation itself. A number of validation processes were developed, not least the use of member checking (Maxwell, 2005) through, in this case, respondent validity (Lincoln \& Guba, 1985) which in turn leant weight to a claim of inter-rater reliability (Litchman, 2010). It was important, too, to consider the consequential validity of the research (Lewis-Beck, Bryman \& Liao, 2004). No trace in references This addresses both the possible intended and unintended consequences of the research upon the broad context in which the research takes place, effects on the participants and the organisation itself. The major results of this research have been reported to the corporation, with a view to enabling it to take an informed position when planning and developing their work. Other issues that emerged have not been shared. These issues take the form of particular allegations of sexism, ageism and bullying, where the individual interviewees asked for their comments not to be relayed back through the research, for fear of the consequences that may then accrue.

\section{Characteristics of SRP}

In general the disposition of these trainers towards their PTLLS course appeared positive. Some were surprised by the demands placed upon them and responded by seeming frustrated. The data appears to suggest that this frame of mind, though, was transitory and that in response they worked hard to achieve success. Over all, these professional trainers displayed a very positive attitude.

There exist some situations where, whether a person takes an interest or not, whether they care or not, they will find themselves in a position over which they have little control, avoidance or veto. The key interview themes enabled the delineation of a series of characteristics of what we now call situated reflective practice, as follows, each illustrated through excerpts chosen from the transcript data:

\section{(i) Immediate personal constraints}


This first characteristic of SRP is that it can often occur to a number of people within an organisational structure, a big company or corporation. It relates to broad trends, for example, such as organisational restructuring. In this interview excerpt, Paul reflects upon the changes brought about through financial and budgetary constraints:

Paul: 'We have been seriously impacted upon by budget cuts now, which is a company-wide, a nationwide thing. But at a stroke my work-load has effectively doubled, because now I will be having to deliver twice as much training effectively - because we are being cut in half as a training unit.'

This reduction of staffing in the training unit is something that clearly impacts upon Paul's professional role and his perceptions as to how he might, in future, manage his responsibilities. In a similar vein, a common 'situated constraint' is the curtailment of time, as Moira makes clear:

Moira: 'You know, when I finished the course I wanted to come back here [to the training unit], and I wanted to do everything from scratch. I wanted to do the training and do the lesson plans, but here there is certainly no time to do that. It's about balancing priorities, I guess.'

Moira's lack of time appears to be the influencing feature preventing her from making the necessary changes to her lesson plans. The extent to which a heavy workload is the responsibility of the individual or the organisation is, of course, a moot point. What is clear, though, is that she wishes to make changes but feels unable to do so due to the presence of uncontrollable outside influences that draw upon her available time, order her priorities for her.

\section{(ii) 'Not actually happening to me', but one-removed: experience by proxy}

During discussions about events and experiences within the corporation, some participants see change occurring that may not affect them directly, but which they note as part of the circumstances that surround their professional role. In this excerpt, Tania considers the way in which the corporation structures retirement policies, and how these impact upon colleagues:

Tania: 'You have got people who have been told, as has happened twice this week, "You have reached 30 years service, you are only 52 but here is 28 days notice, we don't want you any more". They are just too expensive. And they have introduced one of those pension regulations that says if the company has nowhere for you to go, regardless of your age, you can be got rid of.'

Tania is observing others being affected by company policy and, without saying so, feels the same could happen to her. The change in the use of the regulations may not be 
widespread in the company and so the implications are not clear. The implications are that the long-term plans of many employees may have to be readjusted, a need to reflect upon life plans and possible retirement at an earlier stage.

\section{(iii) Circumstances where the locus of power is separate from the participant}

In this instance, the person is not at the centre of the situation and feels a degree of helplessness to change what is happening. This characteristic of SRP relates to situations where decisions are made at a much higher level within an organisation which are then imposed upon others 'lower down' in the system:

Martin: 'Often you will get word that instructions have come from above that will impact upon you. For example, recently something came out about the dress code, it went around the office that the dress code was being implemented for men to wear shirt and ties, and for women a blouse and suitable attire. ... And this is to apply at anytime, including weekends! Everyone thought this was an absolute joke ... There are decisions that go on way above our heads ...'

Someone who is unknown to him, often referred to as 'they' or 'them up above', makes the decisions affecting Martin. In the excerpt below, Prys was keen to improve on the training process but, in light of the decisions made by others, feels powerless to contribute to the situation. A recurring phenomenon appears to be the disenfranchisement of participants, often occurring with little forewarning:

Prys: 'We delivered training out in Saudi Arabia last year. For the second stage of that course they decided to send students over from Saudi to come here. Everything was short notice, we were told with about a month's notice that we had to design and deliver this new course.'

The roots of Prys's problem appear to lie in the decision-making process at a level considerably above his; decisions that he feels have not been fully communicated. Perceptions of 'us' and 'them' commonly lie within the nature and shape of organisational hierarchies, within the organisational culture. In instances such as these, a 'management dictat' might arouse 'discursive consciousness' and shape the professional reflections in question.

\section{(iv) Issues beyond the organisation}

The organisation itself lies within a broader context of social action and behaviour. In the first interview excerpt below, Richard is contemplating the rapid response needed in training so as to meet contemporary and changing events, both in society generally, and within changing legislation in particular: 
Richard: 'Certainly, in our borough, training is not at the top of the agenda, so it is not given the importance that perhaps it should have. Training seems to go from crisis to crisis, so if there is something in the news ... then we have to provide training for it. There are barriers that people don't understand, and some of the subjects that we are asked to deliver either aren't relevant or are just not a problem. And you will have days when about 15 different things are needed that don't hang together! And you can't do a day's training on 15 bits of legislation, you don't have a proper flowing day.'

Harriett's excerpt, too, discusses wider existing concerns, in this case being the target for heavy-handed, sometimes abusive, humour. Her reflections on this are that this is a general issue and, while elements of it are sharply personal, these are symptomatic of anti-social behaviour indicative of a more common and widespread tendency:

Harriett: 'I guess the biggest thing that affects me, and that I can't do anything about, is my age. People tend to have very preconceived ideas about older people and there is still some prejudice. It is the only thing where it still appears acceptable to bully people in the work place, now that racism and sexism have been taken out of the equation. Okay, typical every day situations - references to me as a Tea Lady, the smell of lavender and stale piss, as it is delicately put, comments which may be made in front of groups of people, some of whom I don't know, as happened at a training day, and in front of Housing Officers with whom I have a professional relationship! Posters put up in each room in the Safer Neighbourhood office made from an A4 photocopy of my ID card stating 'Help the Aged."

\section{(v) Anticipatory - on the horizon}

We see Situational Reflective Practice as a process that extends over a long period of time due to the nature of the phenomenon. For example, the government may announce fiscal cuts to be made in the overall budget and, at first, an employee may wonder if and how - this announcement will affect them. A month later he or she reads that, as part of these financial strictures to make financial savings the corporation will have its budgets cut by twenty percent. Now the person begins to be concerned, questioning whether this will have a direct effect. It is not until another six weeks that they hear officially form senior managers that, yes, jobs are to disappear but, as yet, it is not known which because it is anticipated that natural wastage will be a contributory factor. The reflections in this example happen gradually over a long period of time. So, unlike the traditional reflective practice, which is commonly reactive, SRP is often anticipatory in nature:

Marion: 'I am the deputy for community engagement and it is all part of that process because we were doing motivation and first aid stuff for a mosque for example, outside the job. Well that's all going to go out of the window now 
because we can't do community engagement, because there is not the time, the money or the will.'

Richard: 'Resources is probably the big one, budgets, can we afford to send all these people on courses that is always the question. Does it fall inside your training budget that you have bid for? Resources are going to be the big one and that's pounds, shillings and pence.'

\section{SRP, self- and structural distance}

Putting our findings together raises the following question: Do attempts to reflect about particular, often intractable, situations illustrate differences in 'self-distancing'? In out view, the five key themes represent increasing structural distance in space and time between the reflective practitioner and the professional situation in which they work. We see this to work at two levels, the sense of self-distancing and that of structural distancing.

\section{(i) Provide new insights into self-awareness and self-distance}

Kross et al. (2005) have hypothesised that, when people reflect, their self-perception is critical to their capacities to adapt to situations. They argue that attempts to analyse experiences often fall short because people focus on their feelings from a self-immersed perspective (visualising experiences through their own eyes) rather than a self-distanced one (visualising experiences from an observer's perspective). That is, they become 'immersed', 'brooding' and self-centred and do not adopt an 'outsider' stance, selfdistancing themselves from the immediate circumstances (Grossman \& Kross, 2010). The responses we have received do illustrate this kind of gradient, from 'close-up' immediate worries to distant yet-to-happen anxieties. In part, this relates to the three factors we discussed at the start: the nature of the corporation involved and the setting in which it operates, the social roles, responsibilities and relationships between the members of the workforce, and the personal dispositions and outlooks of the individuals involved. In these instances, as people reflect upon their situation, their 'room for personal manoeuvre' is coloured by their perceptions of the immediacy or distance between themselves and the other relevant parts of the organisation.

It is clear, too, that our sense of situated reflective practice is affect-loaded, discussions and comments are accompanied by a range feelings and emotions. These vary from a degree of 'close-range' outrage, anger and resentment, to more self-distanced forms of resignation, acceptance, understanding and acquiescence. So, within the degrees of 
awareness involved, some respondents rail against impositions by the bureaucracy interviewees, while others understand a rather more detached relationship with the organisation. We were aware of, but asked no direct questions about several issues, for example, length of service, and have treated the group homogeneously. There are very tentative indications to suggest what might generally be expected: there is some small evidence to suggest that some of the most skeptical reflective views came from amongst those serving longest.

\section{(ii) Provide new insights into structural distance}

Structural distance has been defined in terms of supervision structures between managers and 'managees' (Antonakis \& Atwater, 2002) and the hierarchical distance between leader and followers (Avolio, Zhu, Koh \& Bhatia, 2004). Not found in references In this case we use the term in a broader sense, of the perceived distance invoked within their reflections of the distance between 'us' and 'them' within the corporation. In this way, we see our key themes (i) - (v) above to illustrate our interviewees' attitudes and actions in relation to the ways in which they interact with others and with aspects of the system. This exemplifies increasing distances between the reflecting professional and the situational constraints within which they are operating, between situations that are 'near internal' and 'far external'.

No doubt, the context as we describe it - the physical surroundings, the social setting and individual dispositions - all contributes to the quality of reflection of, and on, professional practice. The corporation involved in our research is large, multi-layered and heavily authoritarian. It is an institution that can be seen, in Shields' (1995) terms, to lack readiness to embrace not just reflective practice, but also its implications. The bureaucracy of this corporate workplace, and its emphasis on instrumental accountability, seem to have generated individual approaches where individual practice might challenge 'organisational wisdom'. We see our 'degrees of separation' to entail each respondent's sense of personal agency: how they would act to make changes for themselves and others where they thought they could. More generally, respondents identified their intention to change, but various barriers, mostly institutional, thwarted this. Our five interview themes, then, can be associated with attempts by practitioners to progressively distance themselves from their experiences and thereby achieve a more objective view of their practice (Kondrat, 1999). 


\section{Caveats to the study and implications of Situated Reflective Practice}

The research we report here is one small-scale element of a broader body of work into the training function of a major corporation. The research, which took the form of qualitative interviews, has highlighted contextual differences in reflections among practitioners. While we were investigating the nature of professional reflective practice within this field of corporate training, we became increasingly interested in these expressions of situated reflective practice. The cohort of interviewees is small, the context of the interviews quite subscribed, and so the outcomes can only be limited in scope.

Reflection as a concept has not always received good press, being seen as theoretical, philosophical, impractical, inactive, time- wasting' (Bright, 1995, p71), and it is easy to see these limited insights into organisational structures might be written off as being at odds with the demands of current practice. It is not the case that situated reflective practice has essentially been a route for these interviewees to articulate and apportioning blame for personal shortcomings, although we could see traces of this at times. Rather, we see it as the focus of discussions of the real and potential difficulties that occur during the conduct of professional duties and undertakings, in both individual and group settings.

In our view, the research we report here shows that in-depth research interviews with professionals to investigate their work and learning can play an important part in supporting their reflection in-depth on their practice. As in many fields, it can unlock the tacit knowledge and understanding that individual professionals have of their practice and use this to generate knowledge for future practice (Paget, 2001). In addition, an analysis of the processes involved has the potential to help practitioners be reflexive in Giddens' (1984) terms, promote increased self-awareness as part of a process of making the world comprehensible to oneself and other, of creating accounts of institutional reflexivity. 


\section{References}

Antonakis, J., \& Atwater, L. (2002). Leader distance: A review and a proposed theory. The Leadership Quarterly, 13, 673-704.

Avolio, B. J., Zhu, W., Koh, W. \& Bhatia, P. (2004). Transformational Leadership and Organizational Commitment: Mediating Role of Psychological Empowerment and Moderating Role of Structural Distance, Journal of Organizational Behavior, 25 (8), 951-968.

Bourdieu, P. (1984). Distinction: a Social Critique of the Judgment of Taste, Harvard University Press.

Briggs, S. (1999). Links between infant observation and reflective social work practice, Journal of Social Work Practice, 13(2), 147-56.

Bright, B. (1995). What is 'reflective practice’? Curriculum, 16(2), 69-81.

Fook, J. (ed.) (1996). The Reflective Researcher, St Leonards, Australia, Allen and Unwin.

Fook, J. (1999). Critical reflectivity in education and practice, in Pease, B. and Fook, J. (eds), Transforming Social Work Practice: Postmodern Critical Perspectives, St Leonards, Australia, Allen and Unwin, pp. 195-208.

Fook, J. (2002). Social work: ctitical theory and practice. London: Sage.

Gibbs G (1988). Learning by Doing: A guide to teaching and learning methods. Further Education Unit. Oxford Polytechnic: Oxford.

Giddens, A. (1984). The constitution of society: Outline of the theory of structuration. Cambridge: Polity Press.

Giddens, A. and Pierson, C. (1998). Conversations with Anthony Giddens - Making Sense of Modernity. Polity Press, Cambridge.

Grossmann, I. \& Kross, E. (2010). The Impact of Culture on Adaptive Versus Maladaptive Self-Reflection, Psychological Science 21(8) 1150-1157.

Kolb, D, A. (1984). Experiential Learning: experience as the source of learning and development. New Jersey: Prentice Hall.

Kondrat, M. E. (1999). 'Who is the "self” in self-aware: Professional self-awareness from a critical theory perspective’, Social Service Review, December 1999.

Kross, E., Ayduk, O. \& Mischel, W. (2005). When asking “why” does not hurt: Distinguishing rumination from reflective process- ing of negative emotions. Psychological Science, 16, 709-715.

Lewis-Beck, M, S., Bryman, A and Liao, T, F. (2004). The Sage Encyclopaedia of Social Science Research Methods. London: Sage. 
Lichtman, M. (2010). Qualitative Research in Education: A Researcher's Guide.

London: Sage.

Lincoln, Y, S. and Guba, E. (1985). Naturalistic Inquiry. California: Sage.

\section{Authors, 2011}

Maxwell, J, A. (2005). Qualitative Research Design. An interactive approach. $2^{\text {nd }}$ Ed. Applied Social Research Methods Series Volume 41. London: Sage.

Moon J. (2004). A handbook of reflective and experiential learning theory and practice. London and New York: RoutledgeFalmer.

Paget, T. (2001). Reflective practice and clinical outcomes: practitioners' views on how reflective practice has influenced their clinical practice, Journal of Clinical Nursing, 10 (2), 204-214.

Parton, N. \& O’Byrne, P. (2000). 'What do we mean by constructive social work?', Critical Social Work, 1(2), available online at

www.criticalsocialwork.com/00-2-what-parton.html.

Pease, B. \& Fook, J. (eds) (1999). Transforming Social Work Practice:

Postmodern Critical Perspectives, St Leonards, Australia, Allen and Unwin.

\section{Authors, 2011}

Rennie, D.L. (2009). Constructing Client Agency in Psychotherapy Research. Journal of Humanistic Psychology, 49, 193-206.

Schön D. (1987). Educating the reflective practitioner, San Francisco: Jossey-Bass.

Shields E. (1995). Reflection and learning in student nurses. Nurse Education Today, 15, 452-458.

Taylor, I. (1999). ‘Critical commentary’, British Journal of Social Work, 29(1), 175.

Taylor, C. \& White, S. (2000). Practising Reflexivity in Health and Welfare: Making Knowledge. Buckingham, Open University Press. 